as being unsuitable for the visually impaired, as they made reference either directly or indirectly to the sense of vision. These six items were subsequently re-written by the authors to be functionally equivalent to the original items, and be appropriate for use among the visually impaired. Table 1 contains the six original items alongside the new items that were designed to replace them. Further work is now required to examine the reliability and validity of the six new items.

The first step in this process would be to administer the original 28 items of the DES, along with the six new items, to a sample with normal vision. This would allow for the statistical examination of the relationship between each of the six new items with those items they were designed to replace. Providing the six new items were found to be valid replacements, the amended version of the DES can be recommended for use among the visually impaired, either by clinical administration or, when converted to Braille, by self-report.

Reference

1. Bernstein EM Putnam FW. Development, reliability, and validity of a dissociation scale. J Nerv Ment Dis 1986; 174 : 727-735.

${ }^{*}$ Christopher Alan Lewis

Senior Lecturer in Psychology School of Psychology

University of Ulster at Magee College

Northern Ireland, BT48 7JL.

Martin J Dorahy

Clinical Psychologist

Trauma Resource Centre

North \& West Belfast HSS Trust and

School of Psychology

The Queen's University of Belfast

Northern Ireland, BT7 1NN.

Bridget O'Rawe

Staff Grade Psychiatrist

Mater Hospital, Belfast, Northern Ireland.

Angela O'Rawe

Paediatrician

TMR Health Professionals

Belfast, Northern Ireland.

* Correspondence

\section{Self-esteem in national school children in Ireland}

Dear Editor - As part of a wider study examining alcohol, tobacco, drug use, behavioural problems and depression in National School children in the Mid-West region the decision was taken to incorporate a brief self-esteem scale in this project. However difficulties were encountered in finding a relatively short self-esteem questionnaire using language appropriate for the age of participants in this survey.

In light of these difficulties, the researchers involved decided to use the 14 item self-esteem subscale from the child version of the Child Health Questionnaire (CHQCF87).' The CHQ-CF87 had previously been identified as a useful tool to examine child health in Ireland, and norms produced for its many subscales. ${ }^{2}$ The CHQ-CF87 is designed to be self-completed by children aged ten years and over and covers how the respondent has felt over the past four weeks, using a five point Likert Scale for each question (ranging from "Very good" to "Very bad").

Although normative scores for the CHQ-CF87 have been produced for secondary school children in Ireland, to the authors' best knowledge no data is available on normative scores for National School children on the self-esteem subscale. This information therefore is presented below.

Participants included 5th and 6th class pupils (7th and 8th years of education) in 43 randomly selected National Schools in the Mid-West region. Fifty schools were originally approached. Three schools were newly established and had no children in this age group, while four others declined to participate. Active parental consent was a condition of inclusion in this study. Therefore children whose parents said no to their participation in the research, or who did not return the parental consent form were excluded from this study. Including the nonparticipating schools the response rate was $76.2 \%$.

There were 1,255 children who participated in this study ranging in age from $10-14$ years ( 574 boys and 681 girls). However only two children were aged 14 and so these have been excluded from the analysis below. The mean age of those included was 11.5 years $(s d=0.73$ ).

Table 1 details the mean scores, 95\% confidence intervals and sample sizes for the self-esteem scale by age and gender. Analysis of self-esteem scores using a two-way ANOVA revealed no significant effect for either age or gender. As anticipated one sample $t$-tests comparing the overall scores in this sample with older Irish children ${ }^{2}$ and the older African-American group on which the CHQ-CF87 was originally normed' revealed that the younger cohort in this study had significantly higher self-esteem scores $(t[1145]=$ $39.38, p<.001 ; t[1145]=9.47, p<.001)$.

Internal reliability of this scale was adequate (Cronbach Alpha $=.894$ ). Pearson correlations between the 14 items on this scale were all significant ( $p<.001$ between all items), ranging from .178 to .640 . Principal components factor analysis followed by normalised varimax rotation identified two factors each comprising seven items, accounting for $50.4 \%$ of the variance. These may be termed the global self-esteem factor (25.23\%; items 1, 2, 7, 8, 9, $10 \& 14)$ and the interpersonal relations factor ( $25.21 \%$; items $3,4,5,6,11,12$ \& 13).

Correlations with two depression inventories supported the construct validity of the self-esteem scale. This scale was negatively correlated with both the Children's Depression Inventory Short Form (CDI-S) ${ }^{3}(r=-.668, p<.001, n=$ $1129)$ and the revised four item version of the Center for Epidemiological Studies' Depression Scale for Children $(C E S-D C)^{4-5}(r=-.544, p<.001, n=1124)$. The CHQCF87 self-esteem scale therefore can be considered a useful tool for examining this construct in Ireland and should be considered when a relatively short scale is required for use in populations aged 10 years and over.

\footnotetext{
References

1. Landgraf JM, Abetz L, Ware JE. The CHQ user's manual. Boston, MA: The Health Institute, New England Medical Center, 1996.

2. Houghton F, Gleeson M, Kelleher K. The use of the Child Health Questionnaire (CHQ-CF87) in a rural Irish context. Ir J Psychol 2003; 24: 35-45.

3. Kovacs M. Children's Depression Inventory manual. California: Western Psychological Services, 1992.

4. Weissman MM, Orvaschel H, Padian N. Children's symptom and social functioning
} 


\begin{tabular}{llll}
\hline $\begin{array}{l}\text { Age } \\
\text { Mean (CI) (n) }\end{array}$ & $\begin{array}{l}\text { Total } \\
\text { Boys } \\
\text { Mean (CI) (n) }\end{array}$ & \multicolumn{1}{c}{$\begin{array}{l}\text { Girls } \\
\text { Mean (CI) (n) }\end{array}$} \\
$10-13$ yrs & $85.4(84.7-86.2)(1146)$ & $85.6(84.6-86.7)(523)$ & $85.3(84.2-86.3)(623)$ \\
10 yrs & $87.6(85.0-90.1)(73)$ & $88.2(83.7-92.8)(24)$ & $87.2(84.1-90.4)(49)$ \\
11 yrs & $85.9(84.7-87.1)(488)$ & $86.6(85.1-88.1)(217)$ & $85.3(83.6-87.0)(271)$ \\
12 yrs & $84.7(83.5-85.8)(499)$ & $84.3(82.6-86.0)(229)$ & $85.0(83.4-86.6)(270)$ \\
13 yrs & $85.1(82.8-87.5)(84)$ & $85.7(82.7-88.7)(51)$ & $84.3(80.4-88.1)(33)$
\end{tabular}

self-report scales: comparison of mothers' and children's reports. J Nerv Ment Dis 1980; $168: 736-40$

5. Fendrich $M$, Weissman MM, Warner V. Screening for depressive disorder in children and adolescents: validating the Center for Epidemiologic Studies Depression Scale for Children. Am J Epidemiol 1990; 131: 538- 551.

Frank Houghton

Dept. of Humanities, Limerick Institute of Technology Limerick

Hilary Cowley

Dept. of Public Health, HSE Mid-Western Area Limerick

Fiona Meehan

Mary Immaculate College

Limerick

Kevin Kelleher

Dept. of Public Health, HSE Mid-Western Area

Limerick

Ireland.

\section{Psychiatric morbidity in prisoners}

Dear Editor - I read with interest the large scale study by Linehan et al on Psychiatric Morbidity in Prisoners. This is a very important study because of the large numbers involved and because a structured demographic interview was used. I was looking for information on very important psychiatric diagnosis among prisoners, Pervasive Development Disorders/Asperger's syndrome, and Pervasive Developmental Disorder Not Otherwise Specified as well as Attention Deficit Hyperactivity Disorder. I was surprised not to find any comment on these diagnosis which are so important in modern Forensic Psychiatry.

Scragg and Shah found the rate of Asperger's syndrome in a Secure Hospital between 1.5\% - 2.3\%. This is higher than in the general population. In a pilot study by Curran and Fitzgerald found increased rates of Attention Deficit Hyperactivity Disorder in Mountjoy Prison compared to the general population. As it was a pilot study it needs to be done using larger numbers. It is critical that a study now to be done in an Irish prison population of the Pervasive Developmental Disorders including Asperger's syndrome, Autism, Pervasive Developmental Disorder Not Otherwise Specified, as well as Attention Deficit Hyperactivity Disorder as it is my impression that there are significant numbers of these in prison population who are undiagnosed and of course then by definition not treated.

\section{References}

1.Linehan S., Duffy D., Wright B., Curtin K., Monks S., Kennedy H. Psychiatric morbidity in a cross sectional sample of male remanded prisoners. Irish Journal of Psychological Medicine, 2005, 22(4), 128-132

2.Scragg P., Shah A. Prevalence of Asperger's syndrome in a Secure Hospital. British Journal of Psychiatry, 1994, 165: 679-82.

3.Curran S., Fitzgerald M. Attention Deficit Hyperactivity Disorder in a prison population. American Journal of Psychiatry, 1999, 156, 10, 1664-1665.

Michael Fitzgerald Henry Marsh Professor Child \& Adolescent Psychiatry Trinity College Dublin Ireland.

\section{Pimozide treatment for body dysmorphic disorder}

Dear Editor - McWilliams et a/ are to be commended on their interesting and informative case report on body dysmorphic disorder published in the Irish Journal of Psychological Medicine. ' We have recently treated an outpatient with body dysmorphic disorder and we wish to make some points that may be of interest to your readers, relating to both the phenomenology and pharmacolotherapy of this condition.

In summary, the case is that of a 46 year old married man, newly referred to our outpatient department with no previous contact with the psychiatric services. The initial diagnosis made was that of a major depressive episode with associated obsessional ruminations regarding acne rosacea, subsequently revised to major depression and body dysmorphic disorder. Symptoms of acne rosacea had been present to a varying degree for the previous seventeen years, despite little objective evidence of any skin problems on examination. He had consulted dermatologists and had numerous courses of antibiotic treatment but was never satisfied with the outcome.

The phenomenology was interesting, involving obsessional ruminations regarding the acne rosacea, mirror-checking and social avoidance with associated low self-esteem and depressed mood. Analogous to the phenomenology seen in anorexia nervosa, it was sometimes difficult to establish if the patient's beliefs could be defined as overvalued ideas or delusional in nature.

He was initially treated with sertraline (up to $150 \mathrm{mg}$ per day) and risperidone (up to $6 \mathrm{mg}$ per day) but did not respond. His mood became more depressed and he took an 